\title{
Rapid plasma digoxin assay in outpatients-a useful routine technique?
}

\author{
JOHN SAVILL, * MICHAEL MITCHELL, ^DAVID WOOD, $†$ DENNIS M KRIKLER $\ddagger$ \\ From the Departments of ${ }^{\star}$ Medicine and $†$ Biochemistry, Ealing Hospital, Southall; and the $\ddagger$ Cardiovascular \\ Division, Royal Postgraduate Medical School, Hammersmith Hospital, London
}

SUMMARY In 25 outpatients taking digoxin for chronic atrial fibrillation (established for at least six months) a prospective study identified only one case in which rapid availability of the results of a plasma digoxin assay altered the dose which had already been selected on the basis of simple clinical assessment. No patient received more than $375 \mu \mathrm{g}$ digoxin per day and none showed clinical evidence of toxicity even though seven had renal impairment. Six other patients had poorly controlled ventricular rates requiring larger doses of digoxin, but even in these patients the dose could be selected on clinical grounds alone. Despite the availability of a very rapid fluorescence polarisation immunoassay for digoxin, simple but careful clinical monitoring is an adequate basis for the selection of a suitable dose in most patients taking digoxin for atrial fibrillation.

Radioimmunoassay of plasma digoxin provides clinically valuable information, although the correlation between digoxin concentration and clinical state is imperfect, particularly at each end of the suggested therapeutic range. ${ }^{1}$ The 3 to 4 hour assay time means that further clinic visits or advice by letter or telephone are required by outpatients.

Fluorescence polarisation immunoassay of plasma digoxin concentration takes about 20 minutes $^{2}$ so that clinicians can review treatment at a single clinic visit. The value of rapid outpatient assays of anticonvulsant drugs has been established, ${ }^{3}$ but in other circumstances the availability of a rapid assay may lead to its overuse. ${ }^{4}$ We have assessed the clinical usefulness of a rapid plasma digoxin assay for patients attending a district general hosptial cardiological clinic.

\section{Patients and methods}

We studied 25 euthyroid outpatients aged 50 to 86 years with chronic rheumatic or ischaemic heart disease complicated by atrial fibrillation. The presence of the arrhythmia was confirmed by an electrocardiogram on the study day. In every patient the serum albumin concentration was normal. All

Requests for reprints to Dr D M Krikler, Royal Postgraduate Medical School, 150 Du Cane Road, London W12 0HS.

Accepted for publication 4 June 1985. patients had taken the same dose of digoxin at night for at least four weeks and had taken a prestudy dose around midnight. A blood sample was taken at 9 am the following morning at the clinic.

We used a brief standard questionnaire to assess dose adequacy as low, high, or optimum. An optimum response was defined as an absence of palpitation or symptoms of toxicity ${ }^{1}$ with a resting ventricular rate of 60 to 100 beats per minute. If a dose was thought to be inadequate a proposed increase was recorded. One hour later this clinical assessment was reviewed in the light of plasma potassium and creatinine concentrations, and again when the plasma digoxin concentration was known, to see whether the proposed digoxin dose should be $ᄋ$ changed. When a dose was increased the procedure was repeated after four weeks.

The Abbott TDX fluorescence polarisation immunoassay method was used to measure plasma digoxin. The therapeutic range eight to 10 hours postdose is 1.2 to $2.4 \mathrm{nmol} / 1$ with this assay.

\section{Results}

Thirty two measurements of plasma digoxin were obtained in 25 patients (see Table). All the patients were normokalaemic, though 20 were taking diuretics. Seven had renal impairment (creatinine $120-200 \mu \mathrm{mol} / \mathrm{l}$ ) but their digoxin doses varied 
Table Relation between plasma digoxin concentration and heart rate

\begin{tabular}{|c|c|c|c|c|c|}
\hline \multirow[t]{2}{*}{ Case No } & \multirow{2}{*}{$\begin{array}{l}\text { Previous heart rate } \\
\text { over } 120 \text { beats per min }\end{array}$} & \multicolumn{2}{|c|}{ Initial assessment } & \multicolumn{2}{|c|}{ Increased dose } \\
\hline & & Heart rate & Digoxin (nmol/l) & Heart rate & Digoxin (nmol/l) \\
\hline $\begin{array}{r}1 \\
2 \\
3 \\
4 \\
5 \\
6 \\
7 \\
8 \\
9 \\
10 \\
11 \\
12 \\
13 \\
14 \\
15 \\
16 \\
17 \\
18\end{array}$ & $\begin{array}{l}\text { Yes } \\
\text { Yes } \\
\text { Yes } \\
\text { Yes } \\
\text { Yes } \\
- \\
- \\
- \\
- \\
\bar{Y} \\
\text { Yes } \\
\text { Yes } \\
\text { Yes } \\
\overline{-} \\
\overline{Y e s} \\
-\end{array}$ & $\begin{array}{r}124 \\
122 \\
120 \\
118 \\
112 \\
108 \\
98 \\
92 \\
90 \\
88 \\
86 \\
78 \\
78 \\
70 \\
70 \\
65 \\
62 \\
60\end{array}$ & $\begin{array}{l}0.38 \\
0.35 \\
1.42 \\
0.75 \\
0.60 \\
0.52 \\
1.25 \\
0.35 \\
0.62 \\
0.64 \\
0.82 \\
1.40 \\
1.15 \\
1.30 \\
0.74 \\
1.25 \\
2.82 \\
1.42\end{array}$ & $\begin{array}{l}84 \\
92 \\
70 \\
96 \\
90 \\
78 \\
\overline{80} \\
- \\
- \\
- \\
- \\
- \\
- \\
- \\
-\end{array}$ & $\begin{array}{l}0.95 \\
1.30 \\
2.64^{\star} \\
1.45 \\
0.99 \\
0.72 \\
0.95 \\
- \\
- \\
- \\
- \\
- \\
- \\
-\end{array}$ \\
\hline $\begin{array}{l}\text { Creatinin } \\
19 \\
20 \\
21 \\
22 \\
23 \\
24 \\
25\end{array}$ & $\begin{array}{l}20 \mu \mathrm{mol} / \mathrm{l}: \\
\text { Yes } \\
\text { Yes } \\
\text { Yes } \\
\overline{\text { Yes }} \\
\overline{\text { Yes }}\end{array}$ & $\begin{array}{l}98 \\
88 \\
84 \\
82 \\
78 \\
68 \\
62\end{array}$ & $\begin{array}{l}1.36 \\
2.40 \\
1.10 \\
1.20 \\
2.52^{\star} \\
1.46 \\
1.82\end{array}$ & $\begin{array}{l}- \\
- \\
- \\
-\end{array}$ & $\begin{array}{l}- \\
- \\
- \\
-\end{array}$ \\
\hline
\end{tabular}

^ Concentrations above therapeutic range.

across the whole range seen in the study $(62.5 \mu \mathrm{g}$ on alternate days to $375 \mu \mathrm{g}$ daily) and none showed signs of digoxin toxicity. Knowledge of plasma creatinine and potassium concentrations did not indicate that the proposed maintenance dose should be altered.

All patients in whom heart rate was thought to be less than optimally controlled (cases 1-6) were given an increased digoxin dose and the subsequent response was adequate. In no case did knowledge of the digoxin concentration lead to a change in the proposed management, even in case 3 , in whom the initial concentration was in the therapeutic range.

In one of the 19 optimally controlled patients (case 8) the finding of a digoxin concentration of 0.32 $\mathrm{nmol} / 1$ did alter management since despite a resting heart rate of $92 / \mathrm{min}$ on $125 \mu \mathrm{g}$ daily the patient complained of mild palpitation; this was abolished when a daily dose of $250 \mu \mathrm{g}$ was given and plasma digoxin was $0.95 \mathrm{nmol} / 1$.

Cases 3, 17, and 23 had concentrations just above the therapeutic range but all were well and remained so for at least another four weeks.

\section{Discussion}

Two centuries after Withering's report on digitalis ${ }^{5}$ our small study further emphasises the importance of clinical observation in the use of digoxin. In only one patient in 25 (and one measurement in 32) did the knowledge of a plasma digoxin concentration influence management. Thus, in contrast to the situation with anticonvulsants, which have a similarly narrow therapeutic ratio and fickle reputation, we cannot advocate widespread adoption of a same visit outpatient service for routine digoxin assay for patients with atrial fibrillation attending follow up clinics such as ours.

Retrospective studies have suggested that while clinical judgement should remain the cornerstone of therapy with digoxin, knowledge of plasma concentrations may assist when toxicity is suspected, when atrial fibrillation is refractory to a reasonable dose of digoxin, and when renal function is impaired. ${ }^{6}$ In our study only five concentrations exceeded 1.5 $\mathrm{nmol} / \mathrm{l}$, so it is not surprising that plasma digoxin concentration was not a useful indicator of toxicity. Initially we were surprised to find that no patient showed clinical evidence of toxicity; in the early 1970s we would have expected to find that about $25 \%$ of patients had evidence of digoxin toxicity. ${ }^{16}$ A cautious dose selection policy was shown in the current study -42 of 68 similar patients described in 1970 were taking more than $375 \mu \mathrm{g}$ a day, the maximum dose used in our study. ${ }^{6}$

Although we might have expected to find a knowledge of digoxin concentrations useful in six patients who were "under-digitalised" at follow up, their management based on clinical information was satisfactory. Furthermore, four of seven patients with optimal heart rates but digoxin concentrations below 
$1 \mathrm{nmol} / 1$ had demonstrated benefit from digoxin. Cases 5, 6, and 8 had needed an increased dose of digoxin during the study and case 11 had a documented fast ventricular response rate before digoxin was started. Modest doses of digoxin may result in very low plasma digoxin concentrations but some patients will still respond adequately.

In view of our policy of cautious dose selection, it is not surprising to find that in our seven patients with moderate renal impairment no benefit was derived from a knowledge of plasma digoxin concentration despite the risk of toxicity.

We do not of course deny the potential value of the rapid assay in apparently refractory atrial fibrillation or in patients with evidence of toxicity or where there is the suspicion of poor compliance.

Our conclusion depends in part upon the current dose selection policy which is more conservative than that used 15 years ago; our data imply that this policy is reasonable provided physicians continue to apply their clinical senses with the diligence shown by Withering two centuries ago. ${ }^{5}$

\section{References}

1 Smith TW, Haber E. Digitalis. $N$ Engl $f$ Med 1973; 289: 945-53, 1010-5, 1063-72, 1125-9.

2 Ferreri LF, Raisys VA, Opheim KE. Analysis of digoxin concentrations in serum by fluorescence polarization immunoassay: an evaluation. $f$ Anal Toxicol 1984; 8: 138-40.

3 Marty J, Fullinfaw R, Tuckett R, Trembath P, King J. Evaluation of the provision of rapid drug plasma assays in an outpatient anticonvulsant clinic. Ther Drug Monit 1981; 3: 253-8.

4 Morgan DB. The appropriate use of diagnostic services. (ii) The case for fewer measurements of the plasma sodium concentration: costs and gains. Health Trends 1985; 17: 1-3.

5 Withering W. An account of the foxglove, and some of its medical uses: with practical remarks on dropsy, and other diseases. London: GGJ and J Robinson, 1785.

6 Chamberlain DA. Plasma digoxin concentrations as a guide to therapeutic requirements. In: Davies $D$, Pritchard R, eds. Biological effects of drugs in relation to their plasma concentrations. London: Macmillan, 1973: 135-43. 